\title{
Tool validation: Health professionals' perception of the role for a cardiac rehabilitation program
}

\author{
Mohammad Adel Salahat, Nawal S. Faris \\ Faculty of Allied Medical Sciences, Zarqa University, Zarqa, Jordan \\ Correspondence: Mohammad Adel Salahat. Address: Faculty of Allied Medical Sciences, Zarqa University, Zarqa, J ordan. \\ Email: salahat1@yahoo.com \\ Received: February 15, 2013 \\ Accepted: March 26, $2013 \quad$ Online Published: September 28, 2014 \\ DOI : 10.5430/jnep.v4n12p65 \\ URL: http://dx.doi.org/10.5430/jnep.v4n12p65
}

\begin{abstract}
Background: Complications from cardiovascular diseases represent a major concern to health professionals worldwide. Cardiac rehabilitation programs have proven to decrease disease progression, improve outcomes, and promote a healthy lifestyle. Similar evidence, however, has not been established in many countries, including Jordan. Exploring the health professionals' understanding of the impact that a cardiac rehabilitation program (CRP) can make is necessary to increase stakeholder acceptance. One approach is to use a valid tool is that is focused on establishing a common understanding.

Purpose: This study purpose was to validate a new composite tool that measured the health care professionals' perceived role of cardiac rehabilitation programs, and factors influencing their establishment.

Methods: A purposive sample of 110 health professionals working in clinical settings within Amman, Jordan completed a questionnaire, which was statistically examined for reliability and validity.

Discussion: The resulting five themes (factors) from the internal consistency, principal component analysis and construct validity indicated that the questionnaire is valid and reliable. The emerging factors were: purpose of CRP; factors influencing establishing a CRP; definition of CRP; influence of CRP on health professionals' scope of practice; and how does absence of CRP affect health professionals' practice and patient outcome.

Conclusion: Although the questionnaire is valid and reliable, it needs further study to ensure stability on retesting. There is a need to establish rehabilitation programs that on one hand expand the concept of health care and on the other expand the scope of practice and utilize the resources available within the community.
\end{abstract}

\section{Key words}

Jordan, Cardiac rehabilitation, Cardiovascular patients, Validity, Reliability

\section{I ntroduction}

Cardiovascular (CV) diseases and correlated complications are considered one of the main health concerns to health care professionals and planners worldwide ${ }^{[1]}$. These diseases are still the most prevalent causing mortality and co-morbidity in all countries ${ }^{[2]}$. Every year, nearly 17.5 million individual suffer a stroke or myocardial infarction secondary to $\mathrm{CV}$ conditions ${ }^{[2]}$. It is estimated that one billion people will die from CV condition by $2050^{[3,4]}$. In their effort to limit the negative impact of $\mathrm{CV}$, health professionals and agencies, such as the American Association of Cardiovascular and 
Pulmonary Rehabilitation (AACVPR), have moved steps forward to minimize complications and maximize patient getting back to 'normal life'. In addition to supporting scientific research, these organizations established cardiac rehabilitation programs (CRP), which aimed to minimize the impact of CV and enhance patient outcome. Up-to-date, no CRP has been established in Jordan.

There is increasing evidence that implementing cardiovascular protective activities, such as those included in the CRP, can markedly reduce the risk of disability, death and health care-related expenditures ${ }^{[5]}$. It is believed that in Jordan there is a need to increase health care planners' awareness of the positive impact of these programs on CV patients and the community to promote the establishment of the first CRP.

Rehabilitation of CV patients is a relatively new concept in Jordan. It was embraced by the health care professionals who either studied or worked in different Western countries, such as the United States of America and the United Kingdom. Literature reported that increasing clarity about health professionals' understanding of rehabilitation improves their contribution to inpatient and outpatient health outcome ${ }^{[6,7]}$. However, there is still limited knowledge on health professionals' perceived understanding of CRP- its definition, scope and roles. This may be due to lack of studies in this area and the absence of rehabilitation programs in the country. It is, therefore, helpful to investigate this issue, which constitutes the starting point for the planning and development of a rehabilitation program for CV patients. Achieving this requires the use of a valid and reliable instrument. This study aimed to validate a new instrument that measures health care professionals' perceived factors influencing the establishment of CRPs.

\section{Background}

The WHO in its expert committee in 1964 referred to CRP as the sum of activities that ensure cardiac patients the best possible physical, mental and social conditions required to regain a place in the community and enjoy an active life. These activities include planned physical training activities ${ }^{[8]}$, social meetings with individuals of similar health conditions ${ }^{[9]}$, and patients' psychological condition ${ }^{[6]}$.

Cardiac rehabilitation first appearing in health related journals in the 1940s, the first efforts of the health professionals towards investigating the effect of CRP on patients post cardiac event was investigated in 1953.1During the 1970s, a wide spread of such programs have been witnessed in both Europe and North America ${ }^{[10]}$.

Many health-care organizations have recognized the important role of CRPs in promoting positive, cost-effective, minimization of post cardiac event negative impact on patients' lives, including the American College of Cardiology, the American Heart Association, and the European Heart Association ${ }^{[11]}$. CRP, whether for inpatient or outpatient, has been associated with positive markers ${ }^{[8]}$. These include early discharge, less complications for inpatients, cost-effective management, and better achievement in post discharge drug compliance and better quality of life ${ }^{[12-14]}$. Being autonomous and independent, CV patients usually achieve higher self-confidence, which, in turn, could encourage healthier life style and better productive life ${ }^{[15-17]}$.

The prevalence of cardiovascular diseases in Jordan has increased dramatically in the past three decades accompanied with increased prevalence of co-morbidities, including recurrent admissions due to therapy non-adherence and stroke. Interventions that would limit the negative impact of the disease and its co-morbidity have not been fully addressed. Among these measures is the establishment of cardiac rehabilitation programs. Studies that explore aspects of this delay can be beneficial. One aspect is health professionals' perceived understanding of factors influencing founding a CRP.

\section{Methods}

\subsection{Study sample}

For the purpose of obtaining approvals for recruitment to participate in this study, hospitals were contacted through formal letters. When approvals were granted, the researchers contacted nursing directors, chief physicians, research officers and 
head nurses of the critical, intermediate and coronary units (the units where CV patients usually stay during most of their hospitalization period). Appointments, meetings and field visits were conducted as needed. The average visits were three visits per hospital. The number of hospitals was ten (eight private and two public) out of the total number of 15 hospitals (12 private and three public) that provide health care to CV patients in Jordan.

All health professionals working in critical care units were included in this study (i.e., nurses, physicians, and physiotherapist. Those who had an experience less than one year were excluded from this study as this experience was deemed crucial to formulate an idea about the research topic (i.e., Cardiac Rehabilitation Programs). Furthermore, only professionals who worked in critical care units were included in this study, thus limiting the scope of the study. Although this sample can be viewed as inadequate to reflect the a more comprehensive view, it was deemed by the researcher that those professionals are caring for cardiac patients and have better knowledge in a range of needs that this category of patient might have.

\subsection{Study questionnaire}

Approvals were obtained from the ethical committee of each hospital, and then a purposive sample of health professionals representing eight hospitals within Amman chose to participate voluntarily in the study. More than $85 \%$ of the hospitals providing advanced health services to CV patients in Jordan are in Amman (the capital city). The participants were working at units that admit cardiac patients, including coronary care unit, intensive care unit, and intermediate care unit. The researchers visited the candidates in their units and explained the study purpose. Copies of the study questionnaires were then left in each unit for the candidates to fill and return.

\subsection{Questionnaire validity}

Content validity was undertaken to make sure the appropriateness of the questionnaire items and the relevance to the study purpose. It indicates that the content of the questionnaire reflects a complete range of the attributes under study and is usually undertaken by experts in the field of study ${ }^{[18,19]}$. To estimate content validity, the researchers defined clearly the rehabilitation program by conducting a thorough review of literature and seeking experts' opinions. Literature review was conducted by searching in ProQuest, PubMed, Science Direct, Wiley Online Library, CINAHL and Web of Science in electronic databases. The key words used in this search included 'Cardiac Event', 'Rehabilitation', 'Cardiovascular Patient', 'Complications', 'Patient education', and 'Patient Training'.

The researchers then refined the search by keeping relevant articles and excluding the irrelevant. Thematic analysis was then performed to recover the themes and the related items within these articles. These items were transformed into statements to cover each theme. The recovered themes were as follows: the perceived purpose of CRP; factors influencing establishing a CRP; the perceived scope of CRP; the influence of CRP the health professionals' practice; and how does the absence of a CRP influence patient outcome. The researchers then formulated statements to cover these themes. The result was a questionnaire of 67 statements comprised of statements representing the themes found in the literature. The responses were five-point Likert’s scale ranging from 'Strongly Disagree' to 'Strongly Agree'.

Next, six experts in the area of cardiovascular nursing were consulted to examine the questionnaire design, and items to determine their consistency with the concept 'Cardiac rehabilitation'. Each one rated independently the relevance of each item on the questionnaire using as follows: 1 = not relevant, 2 = somewhat relevant, 3 = relevant, 4 = very relevant). The Content Validity Index was used to estimate the validity of the items ${ }^{[18]}$. All reviewers agreed on the items composing the study questionnaire; all items ranged between relevant and very relevant. This was achieved after three rounds of receiving notes, modifying wording and sending the newly-modified versions.

Face validity indicates the questionnaire appears to be appropriate to the study purpose and content area. It is the easiest validation process to undertake but it is the weakest form of validity. It evaluates the appearance of the questionnaire in terms of feasibility, readability, consistency of style and formatting, and the clarity of the language used ${ }^{[19]}$. Thus, face 
validity is a form of usability rather than reliability. To determine face validity of the questionnaire, ten nurses, who were not included later in the sample, revised the statements. They examined the style and layout of the questionnaire. They assessed the statement for readability, ambiguity and unclear ideas within the statements. They suggested few corrections, which we carried out as these appeared necessary.

Construct validity refers to the degree to which the items on an instrument relate to the relevant theoretical construct ${ }^{[19]}$. Construct validity refers to the degree to which the intended independent variable (construct) relates to the indicator ${ }^{[18]}$. When an indicator consists of multiple items, factor analysis is used to determine construct validity.

Factor Analysis is a statistical method used during instrument development to determine the items closely representing the themes (factors) within the construct, examine items having a high loading on each factor, and then cluster the items into a small number of factors ${ }^{[18]}$. Loading measures the association between each item and its correspondence factor ${ }^{[20]}$. Grouped items are closely related and represent part of the construct ${ }^{[20]}$.

Although, the number of participants required undertaking factor analysis remains under debate, Munro recommended a minimum of five participants per each variable ${ }^{[20]}$. To ensure sample size for the current study and to enable factor analysis to two criteria were measured: Kaiser-Meyer-Olkin (KMO) sampling adequacy; and factor loadings and the correlation between a variable and a factor ${ }^{[21]}$.

Principal Component Analysis (PCA) was adopted in this study. In PCA, total variance is analyzed and Eigenvalue is used to determine the cutoff point. Eigenvalue adopted in here was 1. The cutoff point on the loadings of the factors was .50.

\subsection{Reliability}

Reliability indicates that a questionnaire is consistently measuring an attribute and how well the items conceptually fit together ${ }^{[19]}$. However, it is not sufficient to validate an instrument, because an instrument may be reliable but not valid ${ }^{[22]}$. In this study internal consistency reliability was adopted to examine the inter-item correlations within the instrument and indicates how well the items fit together conceptually ${ }^{[23]}$. This method includes Split-Half and Cronbach's alpha correlation measures. A total score of all items is computed to estimate the consistency of the questionnaire. In Split-Half reliability, all items are divided into two sets and the correlation between both is computed. Cronbach's alpha is the most frequently used reliability statistic to establish internal consistency reliability ${ }^{[21]}$.

\section{Results}

\subsection{The demographic findings}

The total number of participants who completed the questionnaire was 110 with a response rate of $65 \%(n=170)$. Table 1 illustrates the demographic findings of this study. The participants were mainly nurses with limited participation from the other health professions. Nurses represented $84 \%(n=92)$, medicine $9 \%(n=10)$ and physiotherapy $7 \%(n=8)$ of the total number. The majority of the participants were male (69\%) and their academic preparation was mainly bachelor (86\%). The mean age was 31 with $66 \%$ of the participants under the age of 30 . The average experience was 5 years with a range of 1-25 years. When measuring the difference between the different profession, gender, degree, age and experience groups using analysis of variance (ANOVA) test, there was no statistically significant difference between them on the factors and the whole items of the questionnaire.

The presence of insignificant differences between the different groups further emphasizes that the need to establish a well-structured CRP that serves patients is common among all the participants who represent different age, gender and professional groups. 
Table 1. The Demographic Findings of the Participants

\begin{tabular}{llll}
\hline Variable & & $\mathbf{n}$ & $\mathbf{\%}$ \\
\hline \multirow{3}{*}{ The profession } & Nursing & 92 & 84 \\
& Medicine & 10 & 9 \\
Gender & Physiotherapy & 8 & 7 \\
& Male & 76 & 69 \\
Age & Female & 34 & 31 \\
& $21-30$ & 72 & 65 \\
& $31-40$ & 17 & 16 \\
Academic preparation & $41-50$ & 15 & 14 \\
& $>51$ & 6 & 5 \\
& Diploma & 8 & 7 \\
Clinical experience (years) & Baccalaureate & 94 & 86 \\
& Masters & 7 & 6 \\
& PhD & 1 & 1 \\
& $1-5$ & 76 & 69 \\
& $6-10$ & 20 & 18 \\
\hline
\end{tabular}

\subsection{Psychometric properties of the questionnaire: normality, reliability and validity}

Cronbach's Alpha was calculated for the instrument to determine internal consistency of the scale. The internal consistency value on Cronbach's Alpha for the questionnaire was .978 with a range of 0.919-0.944 for the five factors, which represent good values. Accordingly, starting factor analysis is a reasonable step ${ }^{[24]}$.

A principal components analysis with Varimax rotation was performed with the original 67 statements of the questionnaire. Based on the theoretically-derived factors a five-factor solution was extracted. The resulting number of statements, which yielded loading above the cutoff point of 0.50, was 54 (see Table 2).

The first factor (9 items) explained more than $71 \%$ of the total variance with Eigenvalue 1 or more (see Table 3 ). The KMO measure of sampling adequacy was 0.870 indicating a high level of inter-correlation among the items and an adequate sample size ${ }^{[25]}$. This result was consistent with Bartlett's test of sphericity, which showed that the correlations between the items were sufficient to perform factor analysis, approximate Chi-Square of $5440.43(p<.000)$. The communality values ranged between 0.696 and 0.884 . Guttman Split Half coefficient was 0.87, which is an acceptable item correlation value. The inter-correlation values of all items had values less than .30, which indicate that the level of inter-correlation among the questionnaire items is acceptable, and not high enough to affect the internal consistency values ${ }^{[24]}$. High internal consistency values usually result from high inter-correlation among items on the scale indicating overlapping items.

The scores were close to normal distribution (Skewness $=-0.302$, Kurtosis $=0.709$, Komolgrov-Smirnov $=0.066$ [the lower bound of the true significance is 0.200$]$ ). Normality in this case is accepted; it is often rejected when kurtosis is higher than \pm 2 and/or skewness is higher than \pm 1 indicating that the distribution departs significantly from the normal distribution ${ }^{[23]}$. Furthermore, the total area under the receiver operating characteristic curve was 0.783 ; this value is considered an acceptable one ${ }^{[26]}$. 
Table 2. The Results of the Five Factor Solution and the Internal Consistency Values*

1. The perceived purpose of CRP $(\alpha=.920)$

Controlling psychological problems

Loadings

Controlling physical problems

Improving mental \& psychological wellbeing

.771

Promoting understanding of prognosis

.769

Enhancing active participation

Facilitating long-term care

.705

Active care during hospitalization

.655

Understanding disease process

Avoiding misleading beliefs

2. Factors influencing establis

Open channels of communication among professionals 833

Decision-makers awareness of CRP

Knowledge of CRP on facility reputation

Resources for training on CRP skills

Rehabilitation training activities

Discussing CRP

Knowledge of CRP impact on health outcomes $\quad .716$

Teamwork key factor to successful CRP $\quad .715$

Supporting CRP establishment $\quad .695$

Regulations to develop CRP $\quad .666$

Staff can establish CRP

\section{The perceived scope of CRP $(\alpha=.942)$}

Medical follow-up

Long-term process

Nutritional plans

Improves knowledge in therapeutic plan

Community-based activities

Basic occupational therapy

Meeting the psycho-social needs

.644

Multidisciplinary effort

Group activity to similar health conditions

Training

.588

Physical activities

Works for all patients

Individualistic

Commences with admission $\quad .525$

Follow-up after discharge

4. The influence of CRP on the health professionals' practice $(\alpha=.944)$

Multidisciplinary communication

Sense of usefulness

Improves multidisciplinary work

Extends practice till after discharge

Enhances professional experience

Participation improves health outcome

Enriches practice

5. How the absence of a CRP influence patient outcome $(\alpha=.944)$

Prevents functional deficits

Improves health outcome

Increases participation in social activities 
Table 3. Total Variance Explained of the five factors

\begin{tabular}{lllllll}
\hline \multirow{2}{*}{ Factor } & \multicolumn{2}{l}{ Initial Eigenvalues } & \multicolumn{3}{l}{ Extraction sums of squared loadings } \\
\cline { 2 - 7 } & Total & \% of variance & Cumulative \% & Total & \% of Variance & Cumulative \% \\
\hline 1 & 3.583 & 71.662 & 71.662 & 3.583 & 71.662 & 71.662 \\
2 & .688 & 13.764 & 85.425 & & & \\
3 & .441 & 8.817 & 94.242 & & \\
4 & .188 & 3.764 & 98.006 & & \\
5 & .100 & 1.994 & 100.000 & & \\
\hline
\end{tabular}

Construct validity of the questionnaire was examined by assessing the collected empirical data for their relatedness to other observed variables in a way that is consistent with theoretically-derived predictions ${ }^{[27]}$. Factor analysis, selecting items of powerful representation, setting high cut-off value were all carried out to ensure the psychometric properties and construct validity of the questionnaire. The deletion of overlapping items, items of weak representation, and irrelevant items added to the statistically-supported values. According to the overall interpretation of the abovementioned procedure and statistical findings the questionnaire used in this study is a valid and reliable instrument.

\section{Discussion}

Based on the results of this study, we have initial support that it measures health professionals' perceived impact of CRP. The factorial analysis, selecting items of powerful representation, setting a relatively high cut-off value are all carried out to ensure the psychometric properties and construct validity of the questionnaire. The deletion of overlapping items, items of weak representation, and irrelevant items added to the statistically-supported values. The result of factor analysis supported by the questionnaire component achieved statistically-accepted values on the loadings above the cutoff point of .50 and the reliability and internal consistency values- Cronbach's Alpha for the scale ranging from .919 to .944. In addition, as it was theoretically predicted these results supported the five predicted factors. Although the items making up each of the five original factors were considered to measure separate constructs, many of those constructs were closely related, and thus the new factor structure (statements) seems logical. Furthermore, construct validity of the instrument was examined by assessing the collected empirical data for their relatedness to other observed variables in a way that is consistent with theoretically-derived predictions ${ }^{[27]}$. All statistical values have then indicated that this instrument is valid and reliable.

On the factors composing the questionnaire of this study, the participants were asked to reflect on their perception regarding the following five factors: (1) the perceived purpose of CRP; (2) factors influencing establishing a CRP; (3) the perceived scope of CRP; (4) the influence of CRP the health professionals' practice; and (5) how does the absence of a CRP influence patient outcome. Similar to findings from other studies, this study suggests that nurses, physicians and physiotherapists have all recognized the crucial role of CRP in the holistic care provided to patient after cardiac events ${ }^{[28]}$.

Although health care professionals have strongly advocated establishing a CRP and reported that decision-makers in their workplaces are aware of the crucial role of the CRP, the lack of priority given by decision-makers and attention by the health workforce all are serious challenges to the development and implementation of a rehabilitation program in Jordan. These challenges have also been reported by Wang and colleagues who also added that the perceived insufficient health care resources and an underdeveloped reimbursement system were other causes for not establishing rehabilitation services in China ${ }^{[29]}$.

Health professionals generally provide information to patients and family members on medication and food modifications while in-hospital, but the contents and depth of this information varied. It is often the practice that little attention is offered to post-discharge plan. This has been espoused with the dramatic decrease in the in-hospital stay as a result of the advancement in the therapeutic plans (e.g. thrombolysis, PTCA, CABG). And then discharge occurs while patients are 
seeking information about the disease and the prospects of life with this new condition ${ }^{[28]}$. Shorter in-hospital stays also diminish the opportunities to counsel patients about risk reduction and exercise. It is, therefore, crucial to provide information and educate patients about the disease process and about health promotion, disease prevention and risk reduction, even after hospital discharge.

In addition, the participants reported that resources and legislations within their facilities were not supportive to the establishment of CRPs. They also indicated that they were willing to incorporate rehabilitation in their work and perform that collaboratively with the other health team members, despite having limited time to do so. Further, health professionals reported that CRP improves and is improved by the formation of multidisciplinary team approach.

Although the majority of participants reported having positive thoughts and ideas about CRP, none of them indicated discussing or working on establishing rehabilitation program any time during their career. This final finding indicates the urgent need to work on practical steps towards establishing a body of health professional interested in establishing the first CRP in Jordan with efforts directed towards its success.

On the effect of CRP, health professionals indiscriminately believed that CRP promotes both their practice and improve patient health outcome, such as the psychosocial, physical and mental health outcomes ${ }^{[7]}$. The result of this service is an active and well-oriented patient to the current and future health status, and the patient potentials and resources that could be used to further improve patients' regaining his/her role in the society ${ }^{[30]}$.

In this study, the participants reported that CRP affects the controllable psychological, mental, and physical problems. It also improves wellbeing, provides evidence for better understanding of patient health condition, and enhances active patients' participation in their care after discharge. CRP nurtures positive efforts from patients to face misleading beliefs about their illnesses. And finally, establishing a rehabilitation program, which is not only effective, but, more importantly, also sensitive to the cultural needs, safe and cost-effective, is needed in Jordan.

\section{Limitations}

The cross-sectional nature of the study design places a number of limitations on the conclusions drawn. It is, therefore, difficult to make claims of causal relationships. The small response rate is another issue that limits the findings in this study. It was decided in a priori to limit the participation to only health professionals working in limited areas, which left a range of other workers who provide care for CV patients outside this study. There, however, is reported literature that a smaller percentage of survey response in homogeneous populations, which is true for this study, is often acceptable.

Another limitation found in this study was related to the experience of the participants. It was found that the majority of participants had an experience of less than five years. This experience might have limited their inputs as related to the research topic. Therefore, it is recommended that similar studies be conducted, perhaps using the same tool developed and validated in this study, on a sample that includes greater variety in terms of both experience and setting.

\section{Conclusion}

The psychometric testing performed in this study indicates that the questionnaire is valid and reliable. However, this is a new instrument that requires further evaluation and possible revision. Validating instruments is an ongoing research activity, and our testing of this instrument can be considered an important contribution to the study of nursing practice.

There is a common agreement among health professionals on the positive role the CRP could have on them, patients and families. This supports the notion for a definition of rehabilitation to be agreed by all professionals groups, but also recognizes the complexities of achieving this. Findings in this study emphasize the fact that establishing a CRP in Jordan 
has become a necessity. This program requires devoted health professionals who would work collaboratively on proposing a comprehensive CRP by setting a well-structured plan to achieve goals as planner.

\section{References}

[1] Eshah N, Bond E. Cardiac rehabilitation programme for coronary heart disease patients: An integrative literature review. International Journal of Nursing Practice. 2009; 15: 131-139. PMid:19531070

http://dx.doi.org/10.1111/j.1440-172X.2009.01738.x

[2] WHO. http://www.euro.who.int.noncummunicable/news/20050628_1. Accessed October 23, 2011.

[3] Rogers A. The Atlas of Heart Disease and Stroke. http://www.who.int/cardiovascular_diseases/resources/atlas/en/. Accessed October 232011.

[4] WHO. 2009a. http://www.who.int/mediacentre/factsheets/fs317/en/index.html. Accessed October 21, 2011.

[5] Wang W, Chair SY, Thompson DR, Twinn SF. Health care professionals' perceptions of hospital-based cardiac rehabilitation in mainland China: an exploratory study. Journal of Clinical Nursing. 2009; 18: 3401-3408. PMid:19886876 http://dx.doi.org/10.1111/j.1365-2702.2009.02876.x

[6] Lau-Walker MO, Cowie MR, Roughton M. Coronary heart disease patients' perception of their symptoms and sense of control are associated with their quality of life three years following hospital discharge. Journal of Clinical Nursing. 2008; 18 : 63-71. PMid:19120733 http://dx.doi.org/10.1111/j.1365-2702.2008.02386.x

[7] Pryor J, Buzio A. Enhancing inpatient rehabilitation through the engagement of patients and nurses. Journal of Advanced Nursing. 2010; 66(5): 978-987. PMid:20337804 http://dx.doi.org/10.1111/j.1365-2648.2009.05237.x

[8] Jiang X, Sit JW, Wong TKS. A nurse-led cardiac rehabilitation programme improves health behaviours and cardiac physiological risk parameters: Evidence from Chengdu, China, Journal of Clinical Nursing. 2007; 16: 1886-1897. PMid:17880478 http://dx.doi.org/10.1111/j.1365-2702.2007.01838.x

[9] Tolmie EP, Lindsay GM, Kelly T, Tolson D, Baxter S, Belcher PR. Are older patients' cardiac rehabilitation needs being met? Journal of Clinical Nursing. 2009; 18: 1878-1888. PMid:19638048 http://dx.doi.org/10.1111/j.1365-2702.2009.02798.x

[10] Clark AM, Whelan HK, Barbour R, MacIntyre PD. A realist study of the mechanisms of cardiac rehabilitation. Journal of Advanced Nursing. 2005; 52: 362-371. PMid:16268840 http://dx.doi.org/10.1111/j.1365-2648.2005.03601.x

[11] Evans JA, Bethell HJ, Turner SC. NSF for CHD: 3 years of 12-month follow-up audit after cardiac rehabilitation. Journal of Public Health. 2006; 28: 35-38. PMid:16251258 http://dx.doi.org/10.1093/pubmed/fdi064

[12] Covinsky KE, Palmer RM, Fortinsky RH, Counsell SR, Stewart AL, Kresevic D, et al. Loss of independence in activities of daily living in older adults hospitalized with medical illnesses: Increased vulnerability with age. Journal of the American Geriatric Society. 2003; 51: 451-458. http://dx.doi.org/10.1046/j.1532-5415.2003.51152.x

[13] Fernandez RS, Salamonson Y, Griffiths R, Juergens C, Davidson P. Sociodemographic predictors and reasons for participation in an outpatient cardiac rehabilitation programme following percutaneous coronary intervention. International Journal of Nursing Practice. 2008; 14: 237-242. PMid:18460065 http://dx.doi.org/10.1111/j.1440-172X.2008.00685.x

[14] Wilson PWF. Cardiac rehabilitation and getting to lipid goals, Journal of Cardiopulmonary Rehabilitation. 2005; 25: $264-265$. PMid:16217228 http://dx.doi.org/10.1097/00008483-200509000-00006

[15] Brown SC, Bechtel GA. Enhancing self-esteem among cardiac patients, Dimensions of Critical Care Nursing. 2000 ; $19: 50-56$. PMid:11998068 http://dx.doi.org/10.1097/00003465-200019050-00013

[16] Davies MJ, Heller S, Skinner TC, Campbell MJ, Carey ME, Cradock S, et al. Effectiveness of the diabetes education and self management programme for ongoing and newly diagnosed (DESMOND) programme for people with newly diagnosed type 2 diabetes: Cluster randomised controlled trial. British Medical Journal. 2008; 336: 491-495. PMid:18276664 http://dx.doi.org/10.1136/bmj.39474.922025.BE

[17] Smith KM, Arthur HM, McKelvie RS, Kodis J. Differences in sustainability of exercise and health-related quality of life outcomes following home or hospital-based cardiac rehabilitation, European Journal of Cardiovascular Prevention and Rehabilitation. 2004; 11: 313-319. PMid:15292765 http://dx.doi.org/10.1097/01.hjr.0000136414.40017.10

[18] Goodwin LD. Changing conceptions of measurement validity: An update on the new standards. Journal of Nursing Education. 2002; 41: 100-106. PMid:11939227

[19] DeVon HA, Block M E, Moyle-Wright P, Ernst DM, Hayden SJ, Lazzara DJ. A psychometric toolbox for testing validity and reliability. Journal of Nursing Scholarship. 2007; 39: 155-164. PMid:17535316 http://dx.doi.org/10.1111/j.1547-5069.2007.00161.x

[20] Munro BH. Statistical method for health care research. 4th edition. Philadelphia: Lippincott, Williams, and Wilkins, 2005. 
[21] Field A. Discovering Statistics using SPSS for Windows. London-New Delhi: Thousand Oaks, Sage publications, 2000.

[22] Pilot D, Hunger B. Nursing research: Principals and methods. Philadelphia: Lippincott Williams \& Wilkins, 1999.

[23] Nunnally JC, Bernstein IH. Psychometric theory. New York: McGraw-Hill, 1994.

[24] Tabachnick BG, Fidell LS. Using Multivariate Statistics. Boston: Pearson/Allyn \& Bacon, 2007.

[25] Kaiser HF, Rice J. Little Jiffy, Mark IV. Journal of Educational and Psychological Measurement. 1974 ; 34 (1): $111-117$. http://dx.doi.org/10.1177/001316447403400115

[26] Fawcett T. An introduction to ROC analysis. Pattern recognition letters. 2006; 27: 861-874. http://dx.doi.org/10.1016/j.patrec.2005.10.010

[27] Streiner DL, Norman GR. Health Measurement Scales. A Practical Guide to Their Development and Use. Oxford: Oxford University Press, 1999.

[28] Atwal A, Tattersall K, Caldwell K, Craik C. Multidisciplinary perceptions of the role of nurses and healthcare assistants in rehabilitation of older adults in acute health care. Journal of Clinical Nursing. 2006; 15: 1418-1425. PMid:17038103 http://dx.doi.org/10.1111/j.1365-2702.2005.01451.x

[29] Wang W, Chair SY, Thompson DR, Twinn SF. Health care professionals' perceptions of hospital-based cardiac rehabilitation in mainland China: an exploratory study. Journal of Clinical Nursing. 2009; 18: 3401-3408. PMid:19886876 http://dx.doi.org/10.1111/j.1365-2702.2009.02876.x

[30] Spasser MA, Greenblatt RB, Weismantel A. Mapping the literature of rehabilitation nursing. Journal of the Library Medical Association. 2006; 94: E137-E142. 